\title{
METHOD OF CHEMICAL FORMULAS COMPARISON
}

\author{
Nataliya A. Vayngolts, Dmitriy M. Korobkin, Sergey A. Fomenkov, Sergey G. Kolesnikov \\ and Alla G. Kravets \\ Volgograd State Technical University \\ Russia, Volgograd, Lenin av., 28
}

\begin{abstract}
To establish the uniqueness of patented technology a patent examiner needs to compare the patent application with the existing patent array documents and make sure there are no present analogs of the suggested invention. Analyzing chemical classes patents requires to compare chemical formulas which can be represented in various formats including MDL, InChI, SMILES, structural formulas, molecular fingerprints. This paper describes the development of a software module that automates the procedures for converting various methods of chemical formulas formalization, chemical formulas contained in a patent application and patent array documents comparison, similar patents revealing based on the results of the comparison of chemical compounds taken from patents. The implemented software module has shown high efficiency (high values of completeness and accuracy for searching patent analogs based on chemical formulas, low values of information loss and information noise) during control check on a test patent array.
\end{abstract}

\section{KEYWORDS}

Chemical Formula, SMILES, InChi, MDL Molfile, Molecular Fingerprint, Patent Database Analysis

\section{INTRODUCTION}

With the increase in the number of patents (more than 20 million patents are registered in the world currently), the time to consider a patent application increases. To establish the uniqueness of patented technology a patent examiner needs to compare it with similar patents (sometimes it's necessary to analyze over a thousand documents) and make sure there are no existing analogs of the invention.

Present automated expert patent examination assistance systems (Korobkin, 2018a) do not provide complete automation of the process (Korobkin, 2018b, p. 48). The expert examines the application and performs a patent search based on the keywords he manually selected from the patent application.

Analyzing chemical classes patents requires to compare chemical formulas (Encyclopedia Britannica, n.d.), i.e. formalized chemical compounds representations that contain information about the atomic composition of a single chemical compound molecule. Chemical formulas can be given in various formats: MDL (MDL Information Systems Inc., 2003), InChI (Heller, 2009), SMILES ("Daylight Theory: SMILES", n.d.), structural formula (Encyclopedia Britannica, n.d.), molecular fingerprint (Dalke, 2008).

The US Patent Office (USPTO) (United States Patent and Trademark Office, n.d.) provides free access to the file storage of patents that contains zip archives with XML files (patent text) and related documents. These documents also include files of the MDL Molfile format which contain a list of chemical compounds.

The MDL Molfile (MDL Information Systems Inc., 2003) chemical table files provide information about atoms, bonds, valences, and coordinates contained in a compound. MDL files consist of a header block, counts line, atom block, bond block, properties block.

The structural formula (Encyclopedia Britannica, n.d.) represents the molecular structure of a chemical compound that shows atomic bonds and how atoms are located in space relative to each other.

The InChI (IUPAC International Chemical Identifier) (Heller, 2009) is an international chemical compounds text identifier that provides a way to encode information on the structure and composition of the molecules. InChI uses many levels to describe a compound: formula, bonds, isotopes, stereochemistry.

The SMILES (Simplified molecular-input line-entry system) specification ("Daylight Theory: SMILES", n.d.) is a system of rules for the unambiguous description of the structure of chemical compounds by ASCII character strings. 
Molecular fingerprinting (Dalke, 2008) is a way to encode the molecule structure. It is a bit string with each bit corresponding to a chemical property, mainly substructures. Molecular fingerprints are commonly used to search for similar chemical compounds.

Thus, the actual problem is to automate the assistance to an expert while considering a chemical class patent application. Since the chemical formulas included in a patent application can be represented in all possible ways (MDL, InChI, SMILES, structural formula, molecular fingerprint, etc.), there is a need to develop automated procedures to convert various methods of chemical formula formalization and compare chemical compound formulas contained in a patent application and patent array documents.

There are four existing analogs for the developed software module: Chemical compounds database "ChemSpider" ("ChemSpider reaches 50 million compound", n.d.); Chemical compounds database "PubChem" ("About PubChem", n.d.); Chemical compounds database "ChemSynthesis" ("Chemical Database - ChemSynthesis", n.d.); Chemical recognition system "NCI/CADD Chemical Identifier Resolver" ("NCI/CADD Chemical Identifier Resolver", n.d.).

As a result of the analysis of the presented analogs, it was decided to develop a software module which performs the following functions: (a) Patent array processing aimed to extract elements of patents descriptions and chemical formulas represented in MDL, SMILES, InChI, structural formulas, molecular fingerprints; (b) Chemical formulas conversion to all representations listed above; (c) Chemical compounds comparison based on molecular fingerprints; (d) Similar patents search based on the results of the chemical compounds comparison contained in the patents.

\section{CHEMICAL CLASSES PATENTS DATABASE FORMING METHODS}

The general algorithm for chemical classes patents database forming that contains information on patents, chemical compounds representations, data on similar chemical compounds and similar patents revealed, is shown in Figure 1.
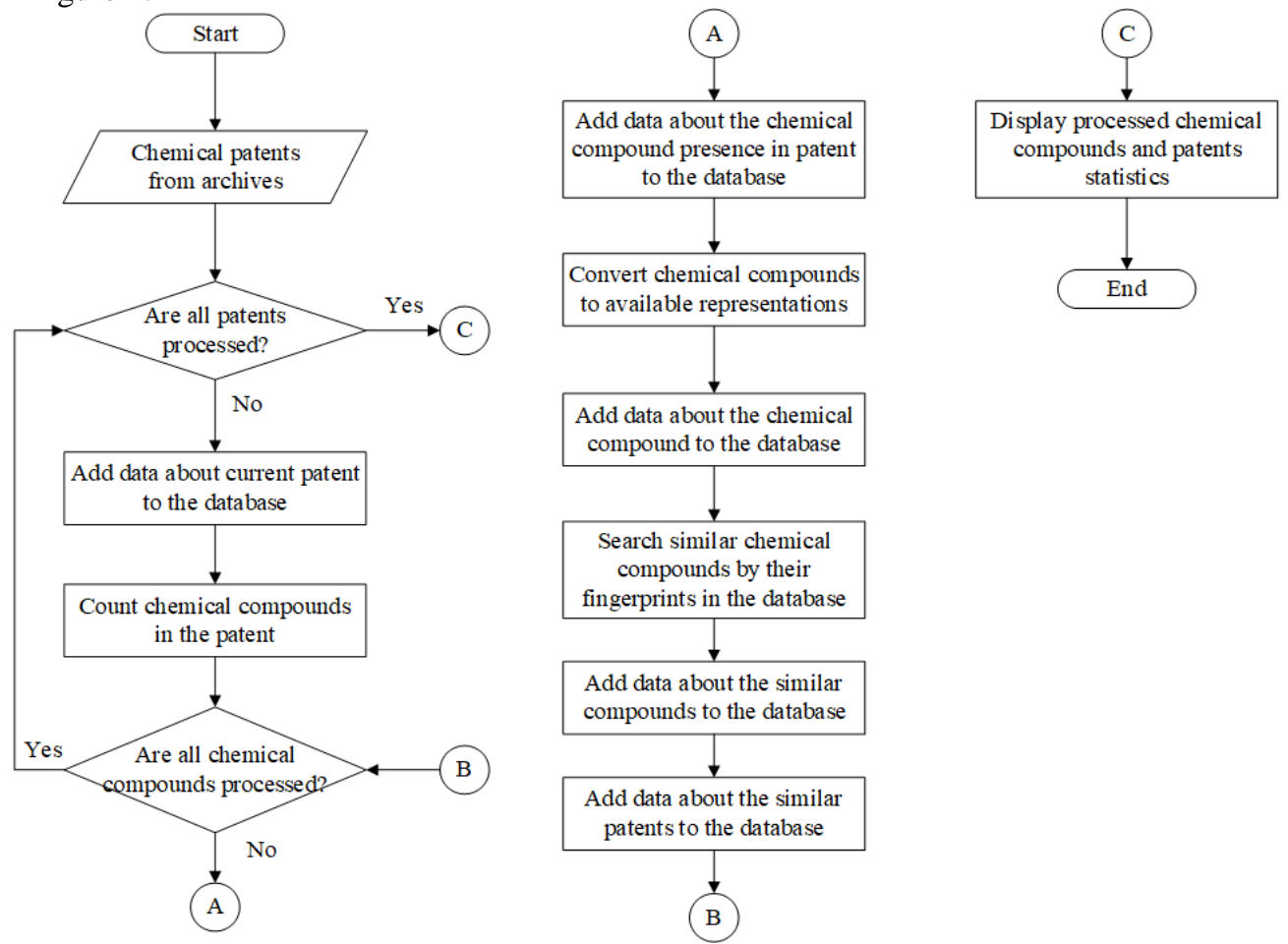

Figure 1. Extracting and writing patent information to the database algorithm

At the initial stage, the information revealing on chemical classes patents (Korobkin, 2018c) and chemical formulas which are contained in the patents is carried out (Korobkin, 2016). 
Then the patent array processing runs chemical patents parsing and writes certain patent characteristics to the database. Chemical compounds contained in the patent are also extracted as their representations and stored in the database.

Before comparison of chemical compounds described in various representations, chemical formulas are converted from MDL Molfile format in SMILES, InChI, structural formulas, molecular fingerprints. The converting chemical formulas in various representations algorithm is shown in Figure 2.

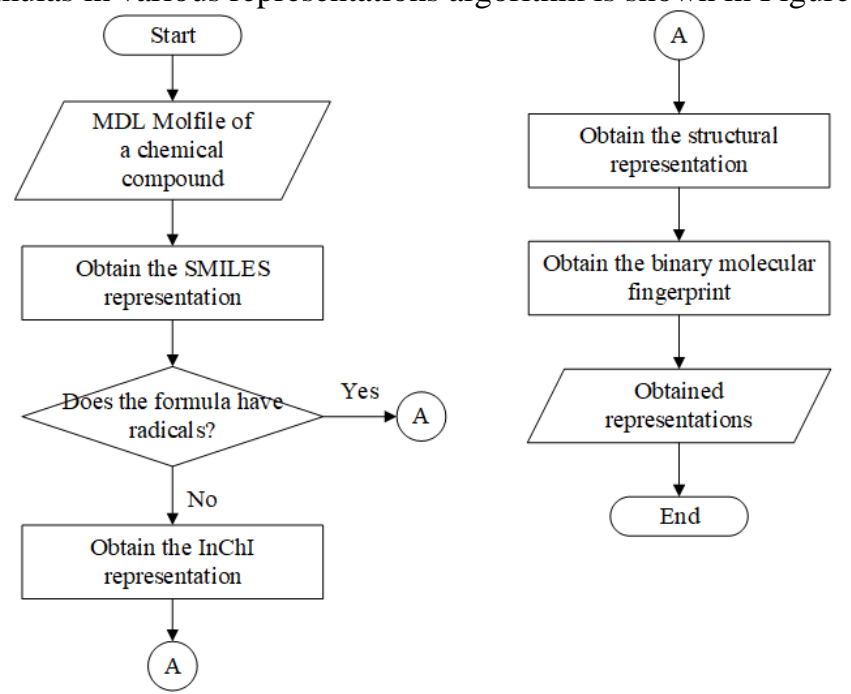

Figure 2. The chemical compounds representations conversion algorithm

\subsection{The Chemical Compounds Comparison Algorithm}

Chemical formulas comparison is based on molecular fingerprints applying. The Tanimoto coefficient ("Tanimoto (cdk 2.1-SNAPSHOT API)", n.d.) is used to calculate their similarity. The Tanimoto coefficient is calculated with the following formula:

$$
T_{S}=\frac{\sum_{i}\left(X_{i} \cap Y_{i}\right)}{\sum_{i}\left(X_{i} \cup Y_{i}\right)},
$$

where $X_{i}$ stands for the $i^{\text {th }}$ bit from the first molecule fingerprint; $Y_{i}$ stands for the $i^{\text {th }}$ bit from the second molecule; $\cap$ stands for bitwise AND; $\cup$ stands for bitwise OR; $T_{S}$ stands for the Tanimoto coefficient for $X$ and $\mathrm{Y}$ fingerprints. The resulting value is in $[0 ; 1]$ range.

Chemical formulas comparison algorithm using molecular fingerprints is shown in Figure 3.

The input of the algorithm serves two binary molecular fingerprints. Chemical formula \#1 has the following SMILES representation: $\mathrm{C} 1=\mathrm{CC}(\mathrm{OC} 1=\mathrm{O})=\mathrm{O}$. Chemical formula $\# 2$ has the following SMILES representation: $\mathrm{C} 1=\mathrm{CC}(=\mathrm{C}(\mathrm{C}(=\mathrm{C} 1 *) *) * \mathrm{O}$.

The chemical formula's \#1 binary molecular fingerprint consists of 48675 characters ( 0 or 1$), 15010$ of them are set. The chemical formula's \#2 binary molecular fingerprint consists of 57960 characters $(0$ or 1$)$, 20440 of them are set. The fingerprints are aligned: zeroes are added to the smaller print until both fingerprints are equal in length.

Then the bitwise "AND" and "OR" are applied to both fingerprints separately; the number of bits set with "AND" and "OR" is calculated. In case molecular fingerprints are identical, the number of set bits after the bitwise "AND" and bitwise "OR" applied will be the same. For the example considered, the number of bits set after operation "AND" applied is 3800 , the number of bits set after operation "OR" applied is 5985 . Their ratio gives a similarity coefficient of 0.634921 . It is considered if the chemical formulas have structural similarity or they do not, depending on the adjusted threshold value for the similarity coefficient. 

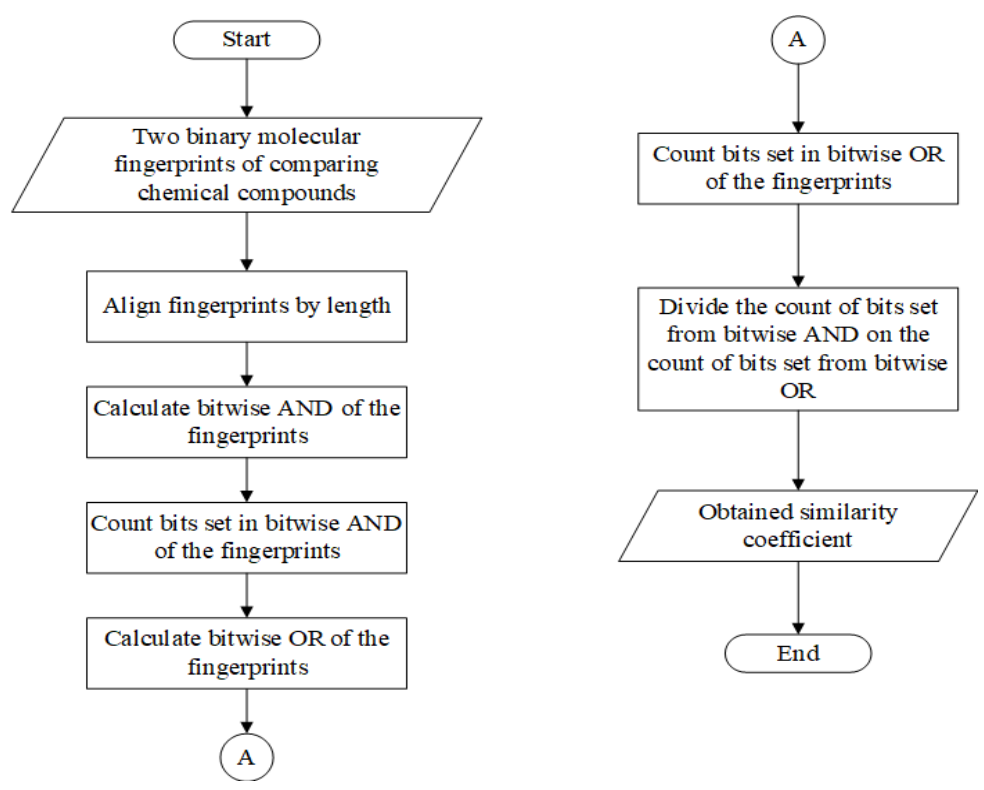

Figure 3. The chemical compounds comparison algorithm

\subsection{The Patents Comparison Algorithm}

Similar patents revealing is made on the basis of the chemical formulas molecular fingerprints comparison performed for the compared patents. The patents comparison algorithm is shown in Figure 4.

Consider the operation of the algorithm presented in Figure 4, step by step. The input of the algorithm serves two patents. Their information cards are presented in Table 1 and Table 2.

Table 1 . The patent \#1 description

\begin{tabular}{ll}
\hline Field & Value \\
\hline Name & Moldable compositions containing carbinol functional silicone resins or anhydride \\
& functional silicone resins \\
Publication number & US07807012 \\
Publication date & 2010-10-05 \\
Applicant & Dow Corning Corporation \\
IPC classification & B29C 67/00; C09J 5/06; C04B 37/00; C08F 283/12; C08G 77/00; C08G 77/38; C08L \\
& 83/00 \\
\hline
\end{tabular}

Table 2. The patent \#2 description

\begin{tabular}{|c|c|}
\hline Field & Value \\
\hline Name & $\begin{array}{l}\text { Isolated aqueous enzymatic preparation and the use thereof for the functionalization of the } \\
\text { surface of paper or cellulosic substrates }\end{array}$ \\
\hline Publication number & US09702087 \\
\hline Publication date & $2017-07-11$ \\
\hline Applicant & $\begin{array}{l}\text { UNIVERSITAT POLITECNICA DE CATALUNYA; RatnerPrestia; Universitat } \\
\text { Politecnica de Catalunya; Nopco Paper Technology Holding AS }\end{array}$ \\
\hline IPC classification & $\begin{array}{l}\text { A61K 38/43; D21H 19/12; D21H 25/02; D21H 17/00; D21H 17/06; D21H 21/14; D21H } \\
\text { 21/16; B05D 1/02; B05D 1/18; D21H 17/14; C12N 9/02; D21H 19/12; B05D 1/02; B05D } \\
\text { 1/18; C12N 9/0061; C12Y 110/03002; D21H 17/005; D21H 17/06; D21H 17/14; D21H } \\
\text { 21/14; D21H 21/16; D21H 25/02 }\end{array}$ \\
\hline
\end{tabular}



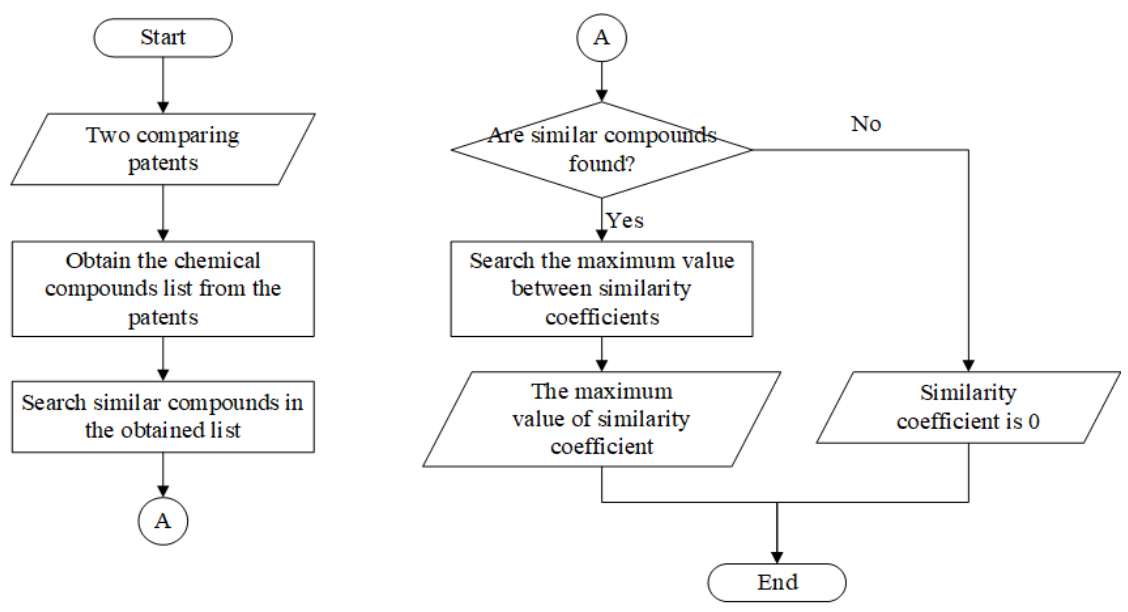

Figure 4. The patents comparison algorithm

Chemical compounds from compared USPTO patents are contained in MDL Molfile files.

The patent \#1 has the following chemical formulas:

1. $\mathrm{C} 1(=\mathrm{CC}(\mathrm{C} 2 \mathrm{C}(\mathrm{C} 1) \mathrm{C}(\mathrm{OC} 2=\mathrm{O})=\mathrm{O})[\mathrm{Si}](\mathrm{C})(\mathrm{C}) \mathrm{OC}) \mathrm{C}$;

2. $\mathrm{C} 1(=\mathrm{CC}(\mathrm{C} 2 \mathrm{C}(\mathrm{C} 1) \mathrm{C}(\mathrm{OC} 2=\mathrm{O})=\mathrm{O}) \mathrm{C}) \mathrm{C}$;

3. $\mathrm{C} 1=\mathrm{CC}(\mathrm{OC} 1=\mathrm{O})=\mathrm{O}$.

The patent \#2 has the following chemical formulas:

1. $\mathrm{C} 1=\mathrm{CC}\left(=\mathrm{C}\left(\mathrm{C}(=\mathrm{C} 1 *)^{*}\right)^{*}\right) \mathrm{O}$;

2. $\mathrm{C} 1=\mathrm{C}\left(\mathrm{C}\left(=\mathrm{C}\left(\mathrm{C}=\mathrm{C} 1 \mathrm{C}(=\mathrm{O}) \mathrm{O}^{*}\right) \mathrm{O} *\right) \mathrm{O}\right)^{*}$;

3. $\mathrm{C} 1\left(=\mathrm{C}\left(\mathrm{C}(=\mathrm{C} 2 \mathrm{C}(=\mathrm{C} 1 *) \mathrm{CCC}(\mathrm{O} 2)(\mathrm{CCC}=\mathrm{C}(\mathrm{C}) \mathrm{CCC}=\mathrm{C}(\mathrm{C}) \mathrm{CCC}=\mathrm{C}(\mathrm{C}) \mathrm{C}) \mathrm{C})^{*}\right) *\right) \mathrm{O}$;

4. $\mathrm{C} 1=\mathrm{C}\left(\mathrm{C}\left(=\mathrm{C}\left(\mathrm{C}=\mathrm{C} 1 \mathrm{C}(=\mathrm{O}) \mathrm{O}^{*}\right) \mathrm{O}^{*}\right) \mathrm{O}\right) *$;

5. $\mathrm{C} 1\left(=\mathrm{C}(\mathrm{C}(=\mathrm{C} 2 \mathrm{C}(=\mathrm{C} 1 *) \mathrm{CCC}(\mathrm{O} 2)(\mathrm{CCCC}(\mathrm{C}) \mathrm{CCCC}(\mathrm{C}) \mathrm{CCCC}(\mathrm{C}) \mathrm{C}) \mathrm{C}) *)^{*} \mathrm{O}\right.$;

6. $\mathrm{C} 1=\mathrm{C}\left(\mathrm{C}\left(=\mathrm{C}(\mathrm{C}=\mathrm{C} 1 \mathrm{C}(=\mathrm{O}) \mathrm{O} *) \mathrm{O}^{*}\right) \mathrm{O}\right) *$;

7. $\mathrm{C} 1=\mathrm{C}(\mathrm{C}=\mathrm{CC}=\mathrm{C} 1) \mathrm{C}(\mathrm{C}=2 \mathrm{C}(=\mathrm{C}(\mathrm{C}=\mathrm{C}(\mathrm{C} 2) \mathrm{C}(\mathrm{C}=3 \mathrm{C}=\mathrm{CC}=\mathrm{CC} 3) \mathrm{C}) \mathrm{C}(\mathrm{C}=4 \mathrm{C}=\mathrm{CC}=\mathrm{CC} 4) \mathrm{C}) \mathrm{O}[\mathrm{H}]) \mathrm{C}$;

8. $\mathrm{C} 1(=\mathrm{CC}=\mathrm{C}(\mathrm{C}=\mathrm{C} 1) \mathrm{OC}=2 \mathrm{C}=\mathrm{CC}(=\mathrm{CC} 2) \mathrm{O}) \mathrm{C}(\mathrm{F})(\mathrm{F}) \mathrm{F}$.

A molecular fingerprint is calculated for each chemical compound file related to a patent. Then a pairwise comparison for the molecular fingerprints from patents \#1 and \#2 between each other runs (Table 3).

Table 3. Comparison of chemical compounds contained in the patents

\begin{tabular}{|c|c|c|}
\hline Chemical formula of patent \#1 & Chemical formula of patent \#2 & $\begin{array}{l}\text { Tanimoto } \\
\text { coefficient }\end{array}$ \\
\hline $\mathrm{C} 1(=\mathrm{CC}(\mathrm{C} 2 \mathrm{C}(\mathrm{C} 1) \mathrm{C}(\mathrm{OC} 2=\mathrm{O})=\mathrm{O})[\mathrm{Si}](\mathrm{C})(\mathrm{C}) \mathrm{OC}) \mathrm{C}$ & $\mathrm{C} 1=\mathrm{CC}\left(=\mathrm{C}\left(\mathrm{C}(=\mathrm{C} 1 *)^{*}\right) *\right) \mathrm{O}$ & 0.564756 \\
\hline $\mathrm{C} 1(=\mathrm{CC}(\mathrm{C} 2 \mathrm{C}(\mathrm{C} 1) \mathrm{C}(\mathrm{OC} 2=\mathrm{O})=\mathrm{O})[\mathrm{Si}](\mathrm{C})(\mathrm{C}) \mathrm{OC}) \mathrm{C}$ & $\mathrm{C} 1=\mathrm{C}\left(\mathrm{C}\left(=\mathrm{C}\left(\mathrm{C}=\mathrm{C} 1 \mathrm{C}(=\mathrm{O}) \mathrm{O}^{*}\right) \mathrm{O}^{*}\right) \mathrm{O}\right) *$ & 0.487217 \\
\hline $\mathrm{C} 1(=\mathrm{CC}(\mathrm{C} 2 \mathrm{C}(\mathrm{C} 1) \mathrm{C}(\mathrm{OC} 2=\mathrm{O})=\mathrm{O})[\mathrm{Si}](\mathrm{C})(\mathrm{C}) \mathrm{OC}) \mathrm{C}$ & $\begin{array}{l}\mathrm{C} 1(=\mathrm{C}(\mathrm{C}(=\mathrm{C} 2 \mathrm{C}(=\mathrm{C} 1 *) \mathrm{CCC}(\mathrm{O} 2)(\mathrm{CCC}= \\
\left.\left.\mathrm{C}(\mathrm{C}) \mathrm{CCC}=\mathrm{C}(\mathrm{C}) \mathrm{CCC}=\mathrm{C}(\mathrm{C}) \mathrm{C}) \mathrm{C})^{*}\right) *\right) \mathrm{O}\end{array}$ & 0.455891 \\
\hline $\mathrm{C} 1(=\mathrm{CC}(\mathrm{C} 2 \mathrm{C}(\mathrm{C} 1) \mathrm{C}(\mathrm{OC} 2=\mathrm{O})=\mathrm{O})[\mathrm{Si}](\mathrm{C})(\mathrm{C}) \mathrm{OC}) \mathrm{C}$ & $\mathrm{C} 1=\mathrm{C}\left(\mathrm{C}\left(=\mathrm{C}\left(\mathrm{C}=\mathrm{C} 1 \mathrm{C}(=\mathrm{O}) \mathrm{O}^{*}\right) \mathrm{O}^{*}\right) \mathrm{O}\right) *$ & 0.458193 \\
\hline $\mathrm{C} 1(=\mathrm{CC}(\mathrm{C} 2 \mathrm{C}(\mathrm{C} 1) \mathrm{C}(\mathrm{OC} 2=\mathrm{O})=\mathrm{O})[\mathrm{Si}](\mathrm{C})(\mathrm{C}) \mathrm{OC}) \mathrm{C}$ & $\begin{array}{l}\mathrm{C} 1(=\mathrm{C}(\mathrm{C}(=\mathrm{C} 2 \mathrm{C}(=\mathrm{C} 1 *) \mathrm{CCC}(\mathrm{O} 2)(\mathrm{CCCC} \\
\left.\left.(\mathrm{C}) \mathrm{CCCC}(\mathrm{C}) \mathrm{CCCC}(\mathrm{C}) \mathrm{C}) \mathrm{C})^{*}\right) *\right) \mathrm{O}\end{array}$ & 0.634921 \\
\hline $\mathrm{C} 1(=\mathrm{CC}(\mathrm{C} 2 \mathrm{C}(\mathrm{C} 1) \mathrm{C}(\mathrm{OC} 2=\mathrm{O})=\mathrm{O})[\mathrm{Si}](\mathrm{C})(\mathrm{C}) \mathrm{OC}) \mathrm{C}$ & $\mathrm{C} 1=\mathrm{C}\left(\mathrm{C}\left(=\mathrm{C}\left(\mathrm{C}=\mathrm{C} 1 \mathrm{C}(=\mathrm{O}) \mathrm{O}^{*}\right) \mathrm{O} *\right) \mathrm{O}\right) *$ & 0.612731 \\
\hline $\mathrm{C} 1(=\mathrm{CC}(\mathrm{C} 2 \mathrm{C}(\mathrm{C} 1) \mathrm{C}(\mathrm{OC} 2=\mathrm{O})=\mathrm{O})[\mathrm{Si}](\mathrm{C})(\mathrm{C}) \mathrm{OC}) \mathrm{C}$ & $\begin{array}{l}\mathrm{C} 1=\mathrm{C}(\mathrm{C}=\mathrm{CC}=\mathrm{C} 1) \mathrm{C}(\mathrm{C}=2 \mathrm{C}(=\mathrm{C}(\mathrm{C}= \\
\mathrm{C}(\mathrm{C} 2) \mathrm{C}(\mathrm{C}=3 \mathrm{C}=\mathrm{CC}=\mathrm{CC} 3) \mathrm{C}) \mathrm{C}(\mathrm{C}=4 \mathrm{C}=\mathrm{CC}=\mathrm{CC} 4) \mathrm{C}) \mathrm{O}[\mathrm{H}]) \mathrm{C}\end{array}$ & 0.598742 \\
\hline $\mathrm{C} 1(=\mathrm{CC}(\mathrm{C} 2 \mathrm{C}(\mathrm{C} 1) \mathrm{C}(\mathrm{OC} 2=\mathrm{O})=\mathrm{O})[\mathrm{Si}](\mathrm{C})(\mathrm{C}) \mathrm{OC}) \mathrm{C}$ & $\mathrm{C} 1(=\mathrm{CC}=\mathrm{C}(\mathrm{C}=\mathrm{C} 1) \mathrm{OC}=2 \mathrm{C}=\mathrm{CC}(=\mathrm{CC} 2) \mathrm{O}) \mathrm{C}(\mathrm{F})(\mathrm{F}) \mathrm{F}$ & 0.473124 \\
\hline
\end{tabular}

For the first chemical formula of patent \#1, the fifth chemical formula of patent \#2 (the Tanimoto coefficient is 0.634921 ) is the most similar.

The ratio of the sum of the Tanimoto coefficient maximum values for compared chemical compounds from a smaller set with chemical compounds from another patent to the size of the least set is taken as the patents similarity coefficient resulting value. 


$$
K_{T}=\frac{\sum_{i} \max _{j} T_{S}}{\min \left(\left|\mathrm{C}_{1}\right|,\left|\mathrm{C}_{2}\right|\right)},
$$

where $\mathrm{C} 1, \mathrm{C} 2$ stand for chemical compounds plurality for patent \#1 and \#2 respectively; $\min (|\mathrm{C} 1|,|\mathrm{C} 2|)$ stands for the minimal size of chemical pluralities for two patents; i stands for enumerating index of the minimum chemical compounds plurality; $\max \mathrm{T}_{\mathrm{S}}$ stands for the Tanimoto coefficient maximum value for the ith chemical compound.

\section{THE SOFTWARE MODULE DESIGN}

The software module (architecture in Figure 5) is implemented in Java with Spring Framework 5.0.1 ("Spring Framework Overview", n.d.) technology. H2 ("Spring Boot and H2 in memory database - Why, What and How?", n.d.) is used as a DBMS for the module due to high-quality integration with the Spring Framework. The Chemistry Development Kit (CDK) ("Chemistry Development Kit", n.d.) library is selected as a collection of processing chemical information tools.

The developed module shows:

- information on patents and chemical compounds contained in patents (Figure 6);

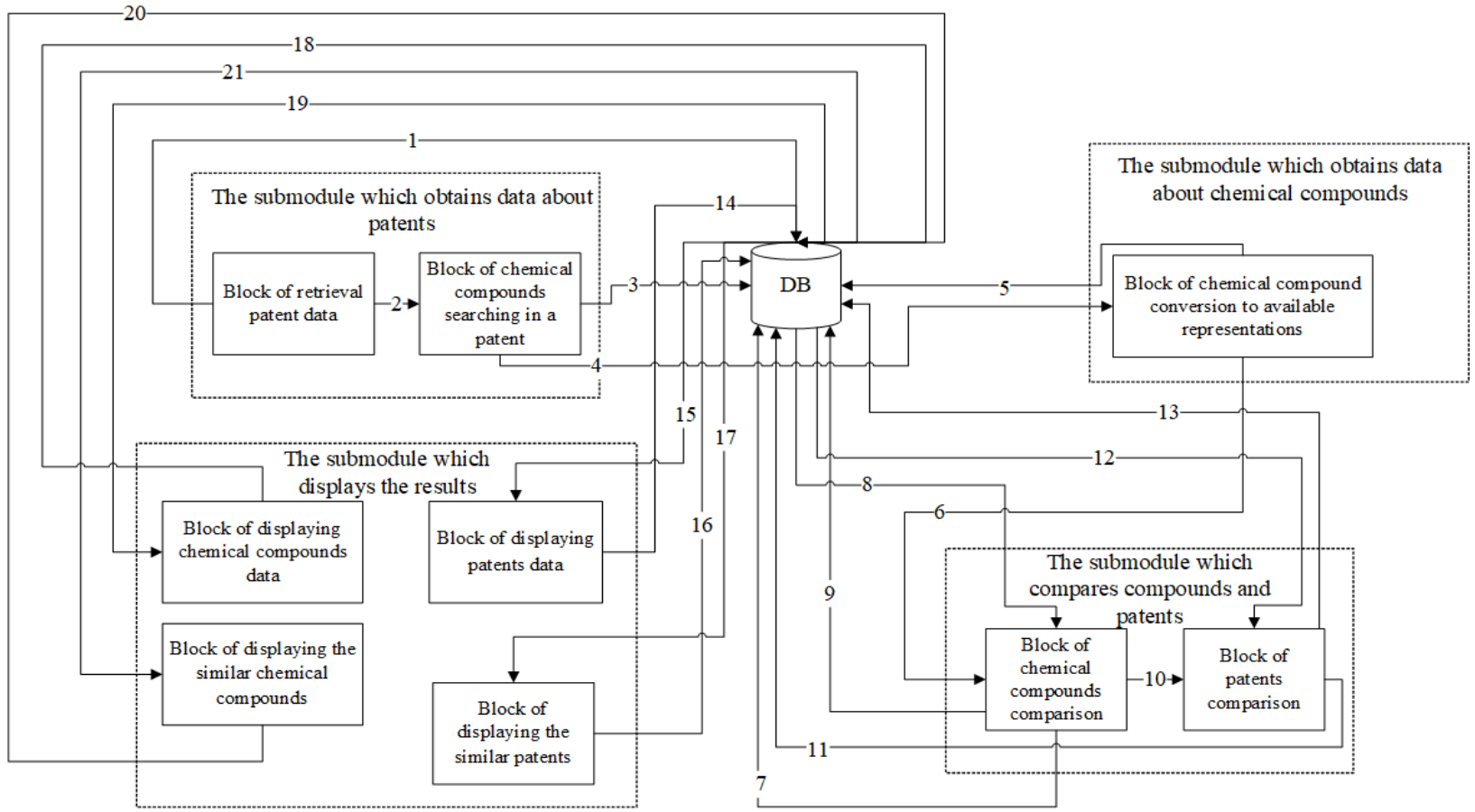

1 - save a record with information about a patent in the database;

2 - call the block of chemical compounds searching in a patent;

3 - save a record with information about chemical compounds present in a patent;

4 - call the block of chemical compound conversion to available representations;

5 - save a chemical compound record in the database;

6 - call the block of chemical compounds comparison;

7 - query to the database to retrieve chemical compounds records;

8 - retrieve chemical compounds records from the database;

9 - save chemical compounds comparison results in the database;

10 - call the block of patents comparison;

11 - query to the database to retrieve patents records;

12 - retrieve patents records from the database;

13 - save patents comparison results in the database;

14 - query to the database to retrieve patents records;

15 - retrieve patents records from the database;

16 - query to the database to retrieve patents similarities records;

17 - retrieve patents similarities records from the database;

18 - query to the database to retrieve chemical compounds

records;

19 - retrieve chemical compounds records from the database; 20 - query to the database to retrieve chemical compounds similarities records;

21 - retrieve chemical compounds similarities records from the database.

Figure 5. Architecture of the module 
- chemical compound characteristics and the list of patents that contain the compound;

- list of chemical compounds similar to the selected compound;

- list of patents similar to the selected patent.

To test the efficiency of the developed module, a sample comprising 53 patents from the list of citations of another 15 patents was compiled.

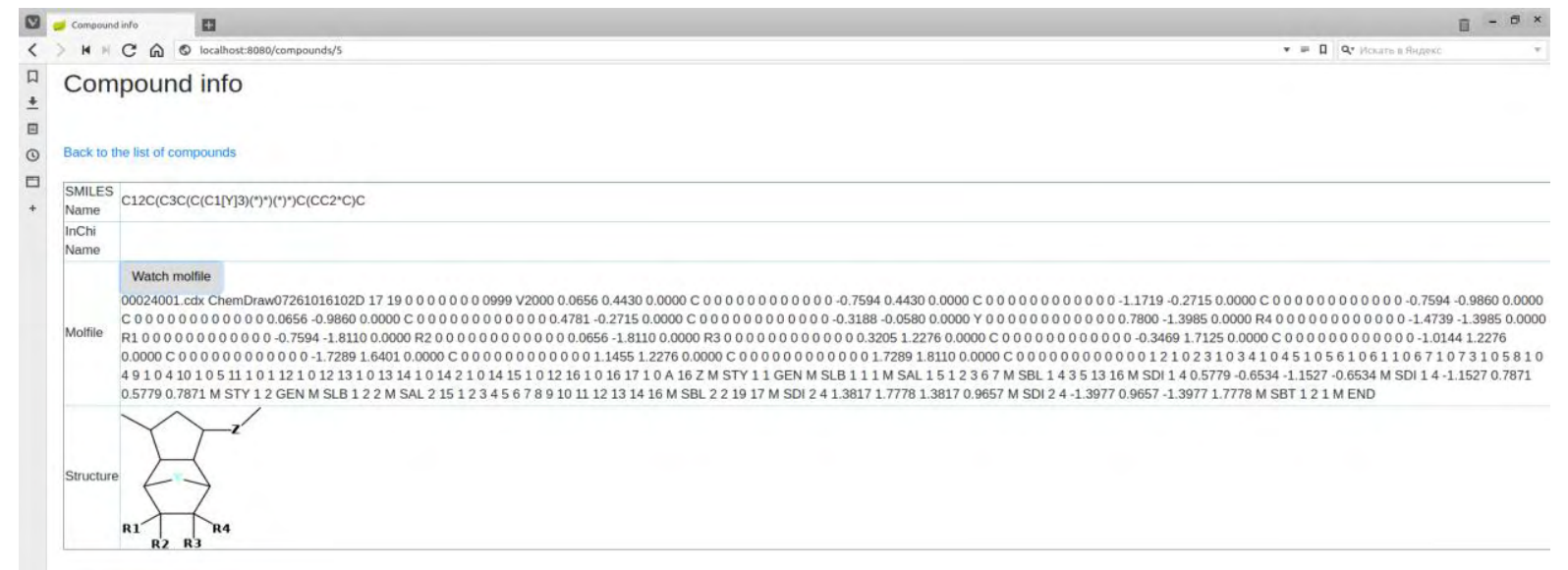

Figure 6. A web page with information about the selected chemical compound

As a result, information on 53 patents and 187 chemical compounds was extracted. 41 pairs of similar patents and 120 pairs of similar chemical compounds were found. Based on the data obtained, the following search performance indicators were calculated (Vayngolts, 2017):

$$
\begin{array}{lll}
\mathrm{R}=\frac{a}{a+c} \times 100 \%, & \text { (3) } & \mathrm{P}=\frac{a}{a+b} \times 100 \%, \\
\mathrm{~L}=\frac{c}{a+c} \times 100 \%, & \text { (5) } & \mathrm{N}=\frac{b}{a+b} \times 100 \%,
\end{array}
$$

where R stands for the patents recall; P stands for the patents precision; $\mathrm{L}$ stands for the losses coefficient; $\mathrm{N}$ stands for the noise coefficient; a stands for the number of relevant patents which were detected; $\mathrm{b}$ stands for the number of irrelevant patents which were detected; $\mathrm{c}$ stands for the number of relevant patents which were not detected; $\mathrm{a}=41, \mathrm{~b}=0, \mathrm{c}=12$.

The recall is $77.3 \%$; the precision is $100 \%$; the losses coefficient is $22.6 \%$; the noise coefficient is $0 \%$.

\section{CONCLUSION}

As a result of the automating chemical formulas comparison module development, the following goals were achieved:

- chemical classes patents database forming methods have been developed;

- converting chemical compounds in various representations, chemical compounds comparison, similar patents search based on the chemical compounds comparison results algorithms have been developed;

- the chemical formulas analysis module has been designed, implemented and tested.

- The next steps to improve the software module:

- development of patents and chemical compounds search by a given key;

- development of a patent search algorithm regarding the list of citations;

- expanding the list of available chemical compounds representations, extracting IUPAC names from patents text;

- chemical classes patents clustering on various features and patents trends prediction. 


\section{ACKNOWLEDGEMENT}

The reported study was funded by RFBR (research projects 18-07-01086, 19-07-01200) RFBR and Administration of the Volgograd region (research projects 19-47-340007, 19-41-340016).

\section{REFERENCES}

About PubChem. [online] Available at: https://pubchemdocs.ncbi.nlm.nih.gov/about [Accessed 18 May 2019].

Chemical Database - ChemSynthesis. [online] Available at: http://www.chemsynthesis.com/ [Accessed 18 May 2019].

Chemistry Development Kit. [online] Available at: https://cdk.github.io/ [Accessed 19 May 2019].

ChemSpider reaches 50 million compounds. [online] Available at: http://www.rsc.org/journals-booksdatabases/librarians-information/librarians-notes/all-articles/2016/jun/chemspider-reaches-50-million-compounds/ [Accessed 18 May 2019].

Dalke, A., 2008. Molecular fingerprints, background. [online] Dalkescientific.com. Available at: http://www.dalkescientific.com/writings/diary/archive/2008/06/26/fingerprint_background.html [Accessed 15 May 2019].

Daylight Theory: SMILES. [online] Available at: http://www.daylight.com/dayhtml/doc/theory/theory.smiles.html [Accessed 15 May 2019].

Encyclopedia Britannica. (n.d.). Chemical formula. [online] Available at: https://www.britannica.com/science/chemicalformula [Accessed 15 May 2019].

Heller, R. and McNaught, A., 2009. The IUPAC International Chemical Identifier (InChI). Chemistry International -Newsmagazine for IUPAC, 31(1).

Korobkin, D., Fomenkov, S., 2018. Method of detection of technical functions performed by physical effects IOP Conference Series: Earth and Environmental Science. Vol. 194 - URL: http://iopscience.iop.org/article/10.1088/1755-1315/194/2/022014/pdf.

Korobkin, D., Fomenkov, S., Golovanchikov, A., 2018. Method of identification of patent trends based on descriptions of technical functions Journal of Physics: Conference Series. - 2018. - Vol. 1015. - 7 p.

Korobkin, D., Fomenkov, S., Kolesnikov, S., Golovanchikov, A., 2016. Technical Function Discovery in Patent Databases for Generating Innovative Solutions In Proceedings of the MCCSIS 2016 ed. by Piet Kommers [etc.], pp. 241-245.

Korobkin, D., Fomenkov, S., Kravets, A., Kolesnikov S., 2018. Methods of Statistical and Semantic Patent Analysis In Proceedings of the CIT\&DS 2017 (Ser. Communications in Computer and Information Science; Vol. 754), pp. 48-61.

MDL Information Systems, Inc., 2003. MDL Information Systems, Inc. CTFile Formats. MDL Information Systems, San Leandro, USA.

NCI/CADD Chemical Identifier Resolver. [online] Cactus.nci.nih.gov. Available at: https://cactus.nci.nih.gov/chemical/structure_documentation [Accessed 18 May 2019].

Spring Boot and H2 in memory database - Why, What and How?. [online] Spring Boot Tutorial. Available at: http://www.springboottutorial.com/spring-boot-and-h2-in-memory-database [Accessed 19 May 2019].

Spring Framework Overview. [online] Available at: https://www.tutorialspoint.com/spring/spring_overview.htm [Accessed 18 May 2019].

Tanimoto (cdk 2.1-SNAPSHOT API) Available at: http://cdk.github.io/cdk/2.1/docs/api/org/openscience/cdk/similarity/ Tanimoto.html [Accessed 18 May 2019].

United States Patent and Trademark Office. [online] Available at: https://bulkdata.uspto.gov/ [Accessed 25 May 2019].

Vayngolts, I., Korobkin, D., Fomenkov, S., Golovanchikov, A., 2017. Synthesis of the Physical Operation Principles of Technical System. In Proceedings of the CIT\&DS 2017 (Ser. Communications in Computer and Information Science; Vol. 754), pp. 575-588. 